\title{
Changing mortality in dilated cardiomyopathy
}

Andrea Di Lenarda, Gabriele Secoli, Andrea Perkan, Dario Gregori, Gerardina Lardieri, Bruno Pinamonti, Gianfranco Sinagra, Massimo Zecchin, Fulvio Camerini, and the ${ }^{\star}$ Heart Muscle Disease Study Group

\begin{abstract}
Objective-To analyse the changes in mortality in dilated cardiomyopathy over the past 15 years and to identify the factors that might have influenced survival. Design-Follow up study of 235 patients (aged 16-70) systematically enrolled on a register from 1 January 1978 to 31 December 1992.

Setting-Hospital department of cardiology.

Patients-Three groups corresponding to three periods of 5 years: group 1 (diagnosis between 1 January 1978 and 31 December 1982) 26 patients; group 2 (diagnosis between 1 January 1983 and 31 December 1987) 65 patients; and group 3 (diagnosis between 1 January 1988 and 31 December 1992) 144 patients.
\end{abstract}

Main outcome measures-Death or heart transplantation.

Results-Two and four year survival was $73.8 \%$ and $53.8 \%$ in group $1,87.7 \%$ and $72.3 \%$ in group 2 , and $90.3 \%$ and $82.9 \%$ in group $3(P=0 \cdot 02)$. During the 15 years of the study period the number of cases increased progressively and the baseline clinical characteristics changed (that is, patients were younger and less severely affected), partly explaining the improvement in survival. None the less, the three mortality curves tended to diverge progressively and the improvement in survival in the different groups was still significant after stratification for the severity of the disease, suggesting that treatment had a sustained effect. A progressively higher proportion of patients were treated with angiotensin converting enzyme (ACE) inhibitors and more recently with $\beta$ blockers. In group 2 , after stratification for the severity of heart failure, patients who were treated with ACE inhibitors showed a better survival than patients who were not. Furthermore, analysis of group 3 showed that $\beta$ blockers had a significant additive effect with conventional therapy both by intention to treat and actual treatment. Four year survival in patients with mild and moderate to severe heart failure treated with $\beta$ blockers, and usually digitalis and ACE inhibitors, was respectively $90 \%$ and $87 \cdot 5 \%$.

Conclusions-The improvement in the survival of patients with dilated cardiomyopathy over the past 15 years may be explained by earlier diagnosis, new treatments, and a change in the clinical characteristics of the patients at enrolment.

(Br Heart f 1994;72 (suppl, Dec:S46-S51)
Dilated cardiomyopathy is a disease of unknown aetiology characterised by low ejection fraction, left ventricular enlargement, and symptoms of heart failure. The variety of its causes and pathogenetic mechanisms may explain the heterogeneity of its clinical presentation, functional status, complications, course, and response to treatment. ${ }^{1}$ In the past the outcome was usually poor, with a median survival of about two years after diagnosis. ${ }^{23}$ More recent studies have indicated that in addition to patients who present in heart failure and rapidly deteriorate and those who die suddenly and unexpectedly, there are others who remain stable for years and who may improve. ${ }^{1}$ Moreover, survival of patients with dilated cardiomyopathy may have been affected by earlier detection of the disease, referral bias, ${ }^{4}$ and new treatments such as angiotensin converting enzyme inhibitors ${ }^{5-8}$ or $\beta$ blockers. ${ }^{910}$ The clinical course of dilated cardiomyopathy in the 1990s may have improved.

We have analysed the changes in mortality in dilated cardiomyopathy over the past 15 years and have tried to identify the factors that could have influenced survival in our study group.

\section{Patients and methods}

PATIENTS

From 1 January 1978 to 31 December 1992 we systematically studied and enrolled in our registry 235 consecutive patients aged 16-70 with dilated cardiomyopathy. Dilated cardiomyopathy was diagnosed, according to the World Health Organisation criteria, ${ }^{11}$ when the angiographic left ventricular ejection fraction was $\leqslant 50 \%$ (normal value in our laboratory $67(8) \%$ mean (SD)) and there was no significant $(>50 \%)$ coronary artery stenosis or other specific heart muscle disease.

All patients had endomyocardial biopsy to exclude active myocarditis (according to the so-called Dallas criteria. ${ }^{12}$ ) We also excluded patients with an alcohol intake $\geqslant 100 \mathrm{~g} /$ day in the previous 6 months or documented systemic hypertension (blood pressure $>170 / 100$ $\mathrm{mm} \mathrm{Hg}$ ).

At diagnosis all patients had physical examination, resting electrocardiogram, chest $x$ ray, 24 hour electrocardiogram monitoring (since 1980), $M$ mode and cross sectional (since June 1982) echocardiogram, haemodynamic and angiographic study, coronary angiography, and endomyocardial biopsy.

Thirty seven variables were recorded at enrolment:

Clinical history-Duration of symptoms of heart failure (months); history of mild hypertension $(\geqslant 140 / 90$ and $\leqslant 170 / 100 \mathrm{~mm} \mathrm{Hg}$ on 
at least two occasions before diagnosis); functional status assessed according to the New York Heart Association (NYHA) classification $^{13}$ and heart failure (HF) score. ${ }^{14}$

Physical examination-Systolic and diastolic blood pressure (mean of the first three measurements at admission), presence of mitral or tricuspid regurgitation or both; third heart sound.

Electrocardiogram-Atrial flutter or fibrillation, PQ interval, left bundle branch block.

Chest $x$ ray-Cardiothoracic ratio.

$M$ Mode echocardiogram-Left ventricular (LV) end diastolic and end systolic diameter index and shortening fraction; left atrium diameter index.

Haemodynamic study-Heart rate, mean right atrial pressure, mean pulmonary artery pressures, mean pulmonary wedge pressure, left ventricular end diastolic pressure, mean aortic pressure, cardiac index, left ventricular stroke volume index, total systemic and pulmonary vascular resistance, left ventricular stroke work index, left ventricular end diastolic and end systolic volume index, left ventricular ejection fraction.

Drug treatments-Digitalis, diuretics, vasodilators, $\beta$ blockers, antiarrhythmic agents, anticoagulants.

The results of treatment with ACE inhibitors or $\beta$ blockers were analysed on an intention to treat basis (prescribed at diagnosis) and according to actual treatment during follow up.

\section{STUDY GROUPS}

We divided the patients into three groups according to their date of enrolment in our registry. Group 1 had DCM diagnosed between 1 January 1978 and 31 December 1982, group 2 between 1 January 1983 and 31 December 1987, and group 3 between 1 January 1988 and 31 December 1992.

End points for follow up were death or heart transplantation. For the purpose of analysis, patients who died or had heart transplantation were regarded as one group. The follow up data were obtained by regular hospital visits and sometimes by telephone contact with patients and their physicians. The study closed on 31 August 1993.

\section{STATISTICAL ANALYSIS}

Thirty seven clinical variables measured at first examination were analysed. Survivor functions from the time of initial evaluation were calculated for each of the three groups by the Kaplan-Meier method. ${ }^{15}$ To maintain the temporal sequence among the groups the significance of the differences between curves was assessed by the trend version of the Tarone-Ware test ${ }^{16}{ }^{17}$-a robust method to take account of departures from the constant hazard ratio assumptions. ${ }^{18}$ The survival curves of the three groups were stratified according to a clinical score that included NYHA, duration of heart failure symptoms, $\mathrm{HF}$ score, ${ }^{14}$ cardiothoracic ratio, left ventricular end diastolic diameter, left ventricular end diastolic volume, and left ventricular ejection fraction. This approach was used to detect any effect of the different treatments in each of the groups, which were heterogeneous for the severity of the disease. Patients were divided into two strata-mild and moderatesevere heart failure-according to this clinical score.

Differences between group means were compared by one way analysis of variance. We used the Cox proportional hazards model to analyse the relation between survival and prognostic indices. ${ }^{19}$ Data are expressed as mean (SD) or a percentage. Results were regarded as statistically significant when $\mathrm{P}<$ 0.05 .

\section{Results}

From 1 January 1978 to 31 December 1992, 235 consecutive patients were enrolled in the study (table 1): 26 patients between 1 January 1978 and 31 December 1982 (group 1); 65 between 1 January 1983 and 31 December 1987 (group 2); and 144 between 1 January 1988 and 31 December 1992 (group 3). Mean follow up was 76 (58) months in group 1,69 (31) months in group 2, and 30 (20) months in group 3. During this period 52 patients died and eight patients had cardiac transplantation. They were included with the dead patients.

Figure 1 shows the survival curves of the three groups. At two and four years cumulative survival was respectively $73.8 \%$ and $53.8 \%$ in group $1,87.7 \%$ and $72.3 \%$ in group 2 , and $90.3 \%$ and $82.9 \%$ in group $3(P=$ $0 \cdot 02)$. The reduction in mortality was evident soon after enrolment and the difference increased during follow up. When patients who survived heart transplantation were analysed as survivors (figs 1 and 2), survival in group 3 was further improved.

Table 1 shows the characteristics of the three groups. During the 15 years of the study there were significant decreases in mean age, duration of heart failure symptoms, NYHA functional class, left ventricular end diastolic diameter index, right and left ventricular filling pressure and a lower incidence of endocardial pacing and left bundle branch block.

Cox proportional hazard analysis showed that the major independent determinants of death or transplantation in the whole study population were left ventricular ejection fraction and duration of heart failure symptoms.

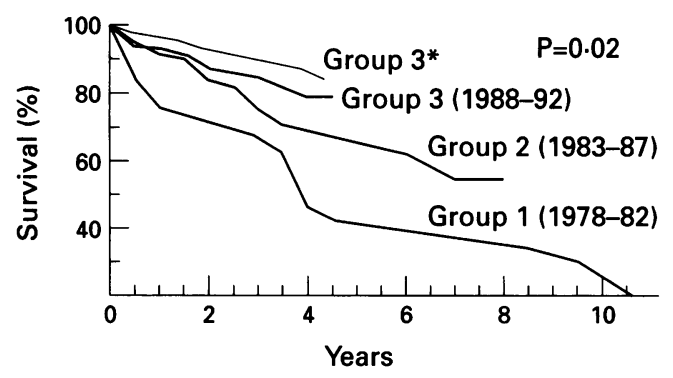

Figure 1 Change in survival of 235 patients with dilated cardiomyopathy in the past 15 years (*when patients surviving heart transplantation were included as "alive".) Group 1, 26 patients; group 2, 65 patients; group 3, 144 patients. 
Figure 2 Change in survival of 235 patients with dilated

cardiomyopathy in the past

15 years analysed by

stratification according to

the severity of heart failure

(see methods) (*when

patients surviving heart

transplantation were

included as "alive".)

Group 1, 26 patients;

group 2, 65 patients; group

3, 144 patients.

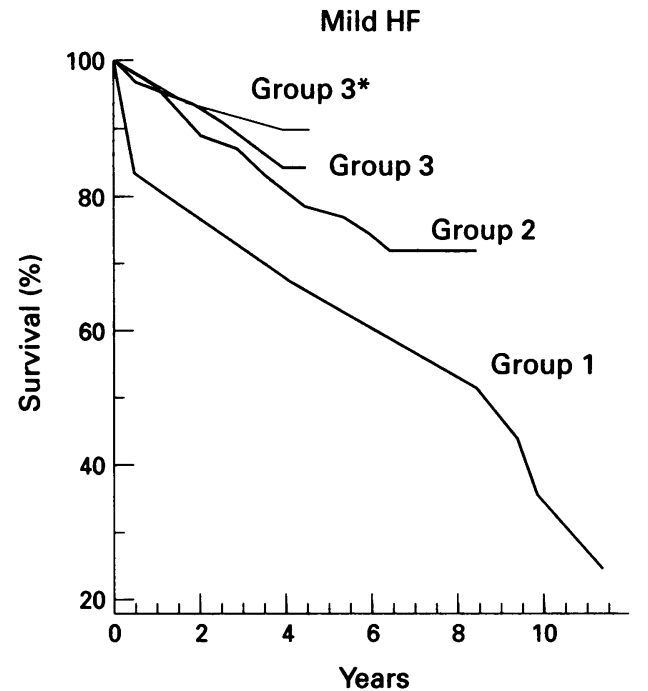

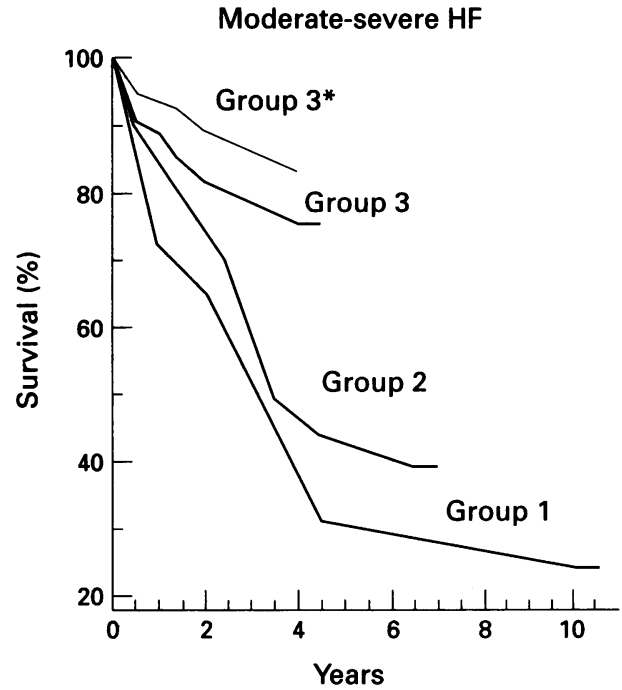

$P=0.046$

We estimated the relative risks for two levels of the independent prognostic factors by comparing the mean values of duration of heart failure symptoms and left ventricular ejection fraction in group 2 and 3 with the mean values in group 1. The relative risk of death was $-35.9 \%$ in group $2 v$ group 1 and $-29.3 \%$ in group $3 v$ group 1 for duration of heart failure symptoms and $-5.3 \%$ and $+11.3 \%$ respectively for left ventricular ejection fraction (table 2).

When the patients of the three groups were stratified according to the severity of heart failure most of the tested variables were similar at both levels of failure (table 3). Furthermore survival in the three groups was still significantly different after stratification for the severity of heart failure and the reduction in mortality was particularly evident in patients with moderate-severe heart failure (fig 2).

The use of ACE inhibitors and of $\beta$ blockers increased over time (table 1). Most of patients of our study population were treated with digitalis $(199 / 235,84 \cdot 7 \%)$ and diuretics $(173 / 235,73.6 \%)$. In one third of the patients in group $2(21 / 65,32 \cdot 3 \%)$ treatment with ACE inhibitors was started at diagnosis (intention to treat analysis) and in another third $(23 / 65,35 \cdot 2 \%)$ it was started during follow up and continued (actual treatment analysis). After stratification for the severity of heart failure the survival curve of group 2 patients treated with ACE inhibitors showed a non-significant tendency to improve by the intention to treat method and a highly significant improvement in survival compared with patients treated with digitalis by actual treatment analysis (fig 3 ).

Moreover, at diagnosis most patients (112 of $144,78.5 \%$ ) in group 3 were treated with $\beta$ blockers usually with digitalis and ACE inhibitors. The survival curves of patients showed that treatment with $\beta$ blockers had a potent additive effect with $A C E$ inhibitors and digitalis alone both by intention to treat and by actual treatment analysis (fig 4 ). 
Figure 3 Survival of 65 patients in group 2 (1983-1987) analysed according to treatment with $A C E$ inhibitors $(A C E-I)$ (table 1) after stratification for the severity of heart failure.
Figure 4 Survival of 144 patients in group 3 (1988-92) analysed according to treatment with $\beta$ blockers (BB) (table 2) after stratification for the severity of heart failure.

Table 2 Cox model of the major independent determinants of death or transplantation among 37 clinical, echocardiographic, and haemodynamic variables in patients with dilated cardiomyopathy

\begin{tabular}{|c|c|c|c|c|c|c|}
\hline & \multirow[b]{2}{*}{$\beta$ Coefficient } & \multirow[b]{2}{*}{$P$} & \multirow[b]{2}{*}{$\begin{array}{l}\text { Exponential of } \\
\text { coefficient }\end{array}$} & \multicolumn{3}{|c|}{ Relative risk (\%) } \\
\hline & & & & $\begin{array}{l}\text { Group } 2 v \\
\text { group } 1\end{array}$ & $\begin{array}{l}\text { Group } 3 v \\
\text { group } 1\end{array}$ & $\begin{array}{l}\text { Group } 3 v \\
\text { group } 2\end{array}$ \\
\hline \multirow{2}{*}{$\begin{array}{l}\text { LV ejection fraction (\%) } \\
\text { Duration of heart failure } \\
\text { symptoms (month) }\end{array}$} & -0.0502 & 0.038 & 0.951 & $-5 \cdot 3$ & $11 \cdot 3$ & $16 \cdot 6$ \\
\hline & -0.0207 & 0.026 & 0.9795 & -35.9 & $-29 \cdot 3$ & $6 \cdot 6$ \\
\hline
\end{tabular}

Relative risk of death or heart transplant in the three groups of patients (the other variable is assumed to be constant for this comparison) was estimated by the following formula: $R R$ (mean value group $x$ - mean value group y) $=$ exponential of coefficient $\times$ (mean value group $x$ - mean value group y).

See footnote to table 1 for abbreviations.

Mild HF

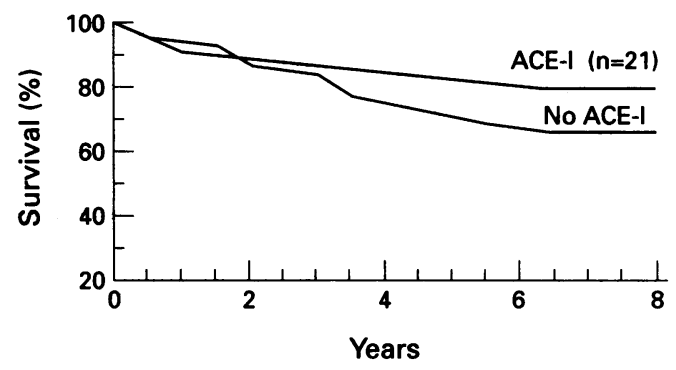

Actual treatment $(P=0.01)$
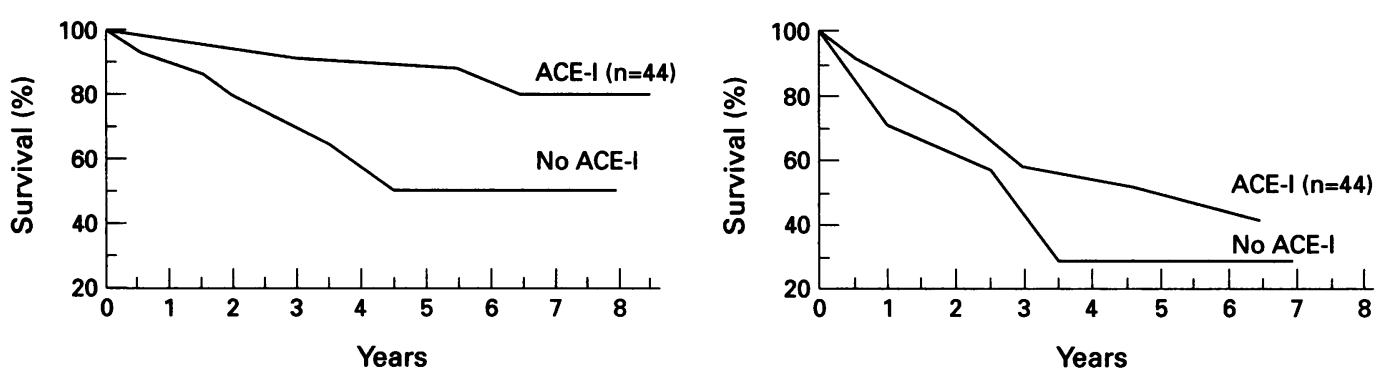

Mild HF

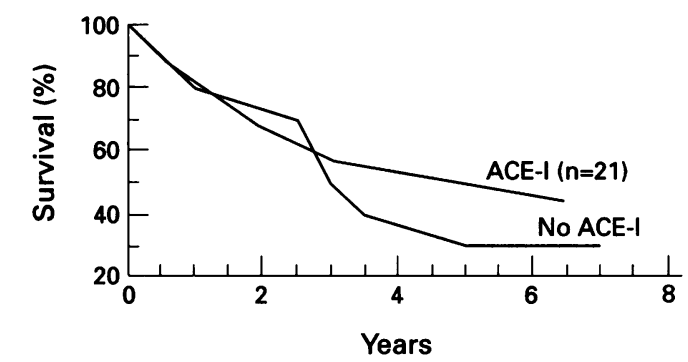

Moderate-severe HF

Intention to treat (P = NS)

Moderate-severe HF
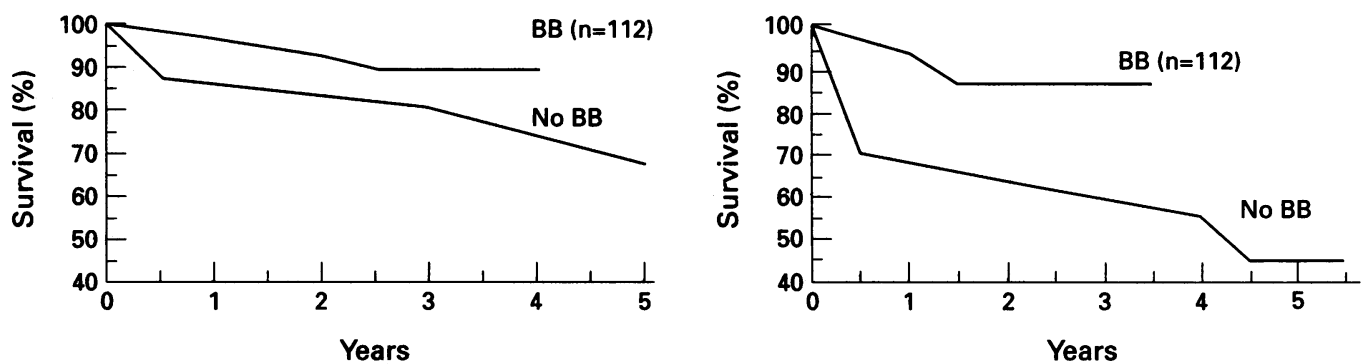

Actual treatment $(P<0.0001)$
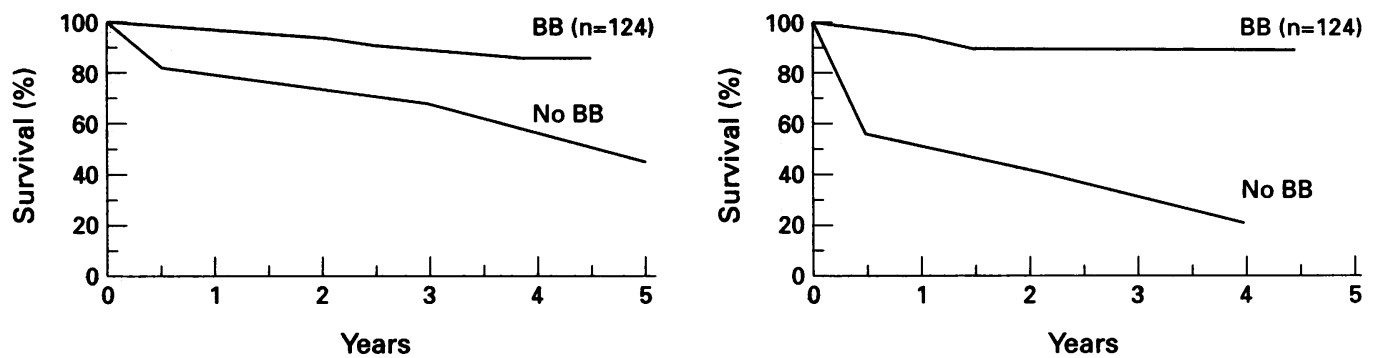
Table 3 Main clinical, echocardiographic, and haemodynamic characteristics in patients with dilated cardiomyopathy stratified according to heart failure severity at diagnosis

\begin{tabular}{|c|c|c|c|c|}
\hline Characteristic & $\begin{array}{l}\text { Group 1 } \\
(1978-82)\end{array}$ & $\begin{array}{l}\text { Group } 2 \\
(1983-87)\end{array}$ & $\begin{array}{l}\text { Group } 3 \\
(1988-92)\end{array}$ & $P$ \\
\hline \multicolumn{5}{|l|}{ Patients (n): } \\
\hline Mild HF & $12 \cdot 00$ & $46 \cdot 00$ & $91 \cdot 00$ & \\
\hline Moderate-severe HF & $14 \cdot 00$ & 19.00 & 53.00 & \\
\hline \multicolumn{5}{|l|}{ Age (yr): } \\
\hline Mild HF & $50 \cdot 50(14 \cdot 40)$ & $46 \cdot 20(14 \cdot 30)$ & $43 \cdot 40(12 \cdot 10)$ & NS \\
\hline Moderate-severe HF & $55.00(13.40)$ & $49.00(13.50)$ & $46.40(13.70)$ & NS \\
\hline \multicolumn{5}{|l|}{ HF symptoms duration (month): } \\
\hline $\begin{array}{l}\text { Mild HF } \\
\text { Moderate-severe HF }\end{array}$ & $\begin{array}{l}17 \cdot 10(25 \cdot 90) \\
44 \cdot 60(31 \cdot 70)\end{array}$ & $\begin{array}{r}9 \cdot 20(17 \cdot 00) \\
24 \cdot 10(30 \cdot 10)\end{array}$ & $\begin{array}{l}12 \cdot 10(18 \cdot 60) \\
25 \cdot 30(35 \cdot 70)\end{array}$ & $\begin{array}{l}\text { NS } \\
\text { NS }\end{array}$ \\
\hline \multicolumn{5}{|l|}{ NYHA: } \\
\hline Mild HF & $1.80(0.60)$ & $1.60(0.70)$ & $1.80(0.60)$ & NS \\
\hline \multirow{2}{*}{\multicolumn{5}{|c|}{ CHF score: }} \\
\hline & & & & \\
\hline Mild HF & $1 \cdot 50(1 \cdot 10)$ & $1.60(2 \cdot 20)$ & $1.60(1.60)$ & NS \\
\hline Moderate-severe HF & $5.00(2.40)$ & $4 \cdot 10(2 \cdot 60)$ & $4.50(2.80$ & NS \\
\hline \multicolumn{5}{|l|}{ Mitral regurgitation (\%): } \\
\hline Mild HF & $50 \cdot 00$ & $41 \cdot 30$ & $60 \cdot 40$ & NS \\
\hline Moderate-severe HF & $86 \cdot 00$ & $\mathbf{7 4} \cdot 00$ & 79.00 & NS \\
\hline \multicolumn{5}{|l|}{ Third heart sound (\%): } \\
\hline Mild HF & $16 \cdot 70$ & $37 \cdot 80$ & $36 \cdot 30$ & NS \\
\hline Moderate-severe HF & $79 \cdot 00$ & $79 \cdot 00$ & $81 \cdot 00$ & NS \\
\hline \multicolumn{5}{|l|}{ Cardiothoracic ratio (\%): } \\
\hline Mild HF & $53 \cdot 70(5 \cdot 10)$ & $53 \cdot 20(9 \cdot 10)$ & $51 \cdot 30(5 \cdot 30)$ & NS \\
\hline Moderate-severe HF & $59.40(5 \cdot 80)$ & $59.50(3.60)$ & $58 \cdot 50(8 \cdot 80)$ & NS \\
\hline \multicolumn{5}{|l|}{ Atrial fibrillation (\%): } \\
\hline Mild HF & $11 \cdot 10$ & $13 \cdot 40$ & $13 \cdot 10$ & NS \\
\hline \multicolumn{5}{|l|}{ Left bundle branch block (\%): } \\
\hline Mild HF & $66 \cdot 70$ & $32 \cdot 40$ & $34 \cdot 50$ & NS \\
\hline Moderate-severe HF & $67 \cdot 00$ & $44 \cdot 00$ & $47 \cdot 00$ & NS \\
\hline \multicolumn{5}{|l|}{ Endocardial pacing (\%): } \\
\hline Mild HF & $8 \cdot 30$ & $8 \cdot 70$ & 0.00 & 0.02 \\
\hline Moderate-severe HF & $7 \cdot 00$ & $10 \cdot 00$ & $4 \cdot 00$ & NS \\
\hline \multicolumn{5}{|c|}{$\mathrm{LV}$ end diastolic diameter index $\left(\mathrm{mm} / \mathrm{m}^{2}\right)$ : } \\
\hline Mild HF & $38.00(5.00)$ & $37.00(5.00)$ & $36.00(3.80)$ & NS \\
\hline Moderate-severe HF & $42.00(5 \cdot 80)$ & $42.00(6 \cdot 10)$ & $40.00(5 \cdot 10)$ & NS \\
\hline \multicolumn{5}{|l|}{ Heart rate (beats/min): } \\
\hline Mild HF & $77 \cdot 00(6 \cdot 70)$ & $85 \cdot 20(16 \cdot 40)$ & $82.00(15.60)$ & NS \\
\hline Moderate-severe HF & $84.80(18.00)$ & $89.40(18.90)$ & $87.50(16 \cdot 20)$ & NS \\
\hline \multicolumn{5}{|c|}{ Mean pulmonary wedge pressure $(\mathrm{mm} \mathrm{Hg})$ : } \\
\hline Mild HF & $9 \cdot 60(6 \cdot 60)$ & $7.60(5 \cdot 70)$ & $10 \cdot 20(6 \cdot 20)$ & NS \\
\hline Moderate-severe HF & $20 \cdot 70(10.80)$ & $13.40(8 \cdot 70)$ & $16 \cdot 40(9 \cdot 10)$ & NS \\
\hline \multicolumn{5}{|l|}{ Mean aortic pressure $(\mathrm{mm} \mathrm{Hg})$ : } \\
\hline Mild HF & $91 \cdot 70(12 \cdot 10)$ & $91 \cdot 70(12 \cdot 80)$ & $89 \cdot 30(11 \cdot 80)$ & NS \\
\hline Moderate-severe HF & $90 \cdot 80(10 \cdot 20)$ & $79 \cdot 10(9 \cdot 80)$ & $83 \cdot 10(10 \cdot 70)$ & 0.01 \\
\hline \multicolumn{5}{|l|}{ Cardiac index $\left(1 / \mathrm{min} / \mathrm{m}^{2}\right)$ : } \\
\hline Mild HF & $3.40(1.00)$ & $3.90(1.20)$ & $4 \cdot 10(1 \cdot 10)$ & NS \\
\hline Moderate-severe HF & $2.90(0.70)$ & $2.70(0.80)$ & $3.00(0.80)$ & NS \\
\hline \multicolumn{5}{|l|}{ Stroke volume index $\left(\mathrm{m} / \mathrm{m}^{2}\right)$ : } \\
\hline Mild HF & $41 \cdot 80(13 \cdot 10)$ & $47 \cdot 80(17 \cdot 80)$ & $51 \cdot 20(15 \cdot 30)$ & NS \\
\hline Moderate-severe HF & $36 \cdot 70(12 \cdot 40)$ & $32.50(10.40)$ & $36 \cdot 00(11 \cdot 20)$ & NS \\
\hline LV stroke work index (g.m.m $\left.{ }^{-2}\right)$ : & & & & \\
\hline Mild HF & $47 \cdot 40(17 \cdot 60)$ & $54.90(23.00)$ & $55.60(19 \cdot 50)$ & NS \\
\hline Moderate-severe HF & $36 \cdot 70(16 \cdot 30)$ & $29.80(13.60)$ & $33.70(13.60)$ & NS \\
\hline LV end diastolic volume index (m & $\left./ \mathrm{m}^{2}\right):$ & & & \\
\hline Mild HF & $116.70(25 \cdot 60)$ & $117 \cdot 70(38.90)$ & $125 \cdot 10(35 \cdot 00)$ & NS \\
\hline Moderate-severe HF & $153.90(42.00)$ & $170.50(66.30)$ & $165.00(58.70)$ & NS \\
\hline LV ejection fraction (\%): & & & & \\
\hline Mild HF & $39.60(8 \cdot 80)$ & $36.80(11.60)$ & $33.80(9.40)$ & NS \\
\hline Moderate-severe HF & $24.30(10 \cdot 50)$ & $23.30(5 \cdot 70)$ & $22.60(6.80)$ & NS \\
\hline
\end{tabular}

See footnote to table 1 for abbreviations.
Data from 15 years ago suggested that patients with the disease usually deteriorated rapidly and that half of them were dead within two years. ${ }^{23}$ The characteristics and survival of these patients resembled those in our patients in group 1 (figs 1 and 2) who were diagnosed in the same period. More recent studies, with earlier detection of the disease ${ }^{4}$ and the use of new treatments (ACE inhibitors, ${ }^{5-8}$ and $\beta$ blockers ${ }^{90}$ ), however, indicated changes in mortality and in the course of dilated cardiomyopathy. We found a significant improvement in survival over the period of our study and that cardiac transplantation increased survival in patients with end stage dilated cardiomyopathy (figs 1 and 2).

We also found a progressive increase in the number of cases of dilated cardiomyopathy and a change in the baseline clinical characteristics (table 1). Patients of groups 2 and 3 were significantly younger, had not had heart failure symptoms for as long, and had less advanced disease, reflected by NYHA functional class, left ventricular end diastolic diameter index, right and left ventricular filling pressure, advanced atrioventricular conduction delay, and left bundle branch block. Like others ${ }^{2}$ 21-24 26-28 we found that many of these variables had prognostic significance and may modify the survival of patients with dilated cardiomyopathy.

A shorter duration of heart failure symptoms and less severe disease may indicate that a different type of patient was selected and an earlier diagnosis. It is likely that at least some of the group 3 patients were identified early, particularly those who were symptom free or had only slight symptoms before diagnosis.

Another factor that could explain an improved survival is the increasing use of new effective drugs. The three mortality curves tended to diverge progressively and the improvement in survival in the different groups remained significant after stratification according to the severity of the disease (fig 2), suggesting that treatment had a sustained effect. A progressively higher proportion of patients were treated with ACE inhibitors and more recently with $\beta$ blockers (table 1 ).

Chronic neuroadrenergic activation and the activation of the renin-angiotensin system caused by myocardial disease may lead to progressive myocardial damage and cardiac death. ${ }^{29-31} \beta$ Blockers, ACE inhibitors, and probably digitalis can reduce the neurohormonal activation particularly in patients with advanced heart failure. ${ }^{32-35}$

Randomised prospective trials have already shown that treatment with ACE inhibitors improves survival in heart failure. ${ }^{5-8}$ Recognition of the deleterious effect of long term activation of sympathetic nervous system increased interest in the use of $\beta$ blockers in the treatment of heart failure. Several small controlled clinical trials showed that $\beta$ blockers can alleviate symptoms and can improve ventricular function and possibly survival in patients with idiopathic dilated cardiomyopathy. ${ }^{9}{ }^{1033-36}$ However, the effect of $\beta$ blockers on survival needs to be confirmed by further clearly different when the earliest manifestations of the disease, the first appearance of subjective symptoms, or the development of cardiac failure were taken as starting points. ${ }^{25}$ 
randomised controlled studies. In our study the increasing use of ACE inhibitors in group 2 was associated with a significant improvement in survival by actual treatment analysis (fig 3). The intention to treat analysis showed a nonsignificant improvement in treated patients (fig 3). In accordance with the Consensus I study $^{6}$ only those patients with more advanced heart failure $(21$ of $65,32.3 \%)$ in group 2 were treated at diagnosis with ACE inhibitors. Later in the study, however, and in the light of other clinical studies, ACE inhibitors were more extensively used. Therefore over half the patients (23 out of $44(52 \cdot 2 \%)$ ) in the control group ("no ACE inhibitors") were in fact treated with ACE inhibitors during follow up. Thus the risk reduction for mortality, determined by intention to treat analysis, probably underestimated the benefits of treatment.

In group $3, \beta$ blockers had a significant additive effect on survival compared with conventional treatment with digitalis and ACE inhibitors. Patients with mild and moderatesevere heart failure, usually treated with the combination of digitalis, ACE inhibitors and $\beta$ blockers, showed a 4 year survival of $90 \%$ and $87 \cdot 5 \%$ respectively, which was clearly better than the survival of the group of patients in whom $\beta$ blockers had not been used (fig 4).

Our study, which was designed to identify changes of the course of dilated cardiomyopathy in the past two decades, seems to show that survival has improved. The study, however, was not randomised and no control patients were followed up. However, because the data analysed were based on a "register of symptoms, circumstances, treatments and outcomes" that was continuously monitored and kept up to date, our use of historical controls is adequate. ${ }^{37}$

Our data explain the changes in survival and this knowledge will help us to inform patients and also plan more active treatments or cardiac transplantation. Better knowledge of the prognosis and of the course of the disease will help with planning pharmacological and clinical trials.

1 Fowles RE. Natural history and prognosis of overt dilated cardiomyopathy. In: Baroldi G, Camerini F, Goodwin $\mathrm{JF}$, eds. Advances in cardiomyopathies. Berlin: SpringerVerlag, 1990:337-46.

2 Fuster V, Gersh BJ, Giuliani ER, Tajik AJ, Brandenburg RO, Frye RL. The natural history of idiopathic dilated cardiomyopathy. Am $\mathcal{F}$ Cardiol 1981;47:525-31.

3 Franciosa JA, Wilen M, Ziesche S, Cohn JN. Survival in men with severe chronic left ventricular failure due to men with severe chronic left ventricular failure due to either coronary heart disease or idiopathic

4 Sugrue DD, Rodeheffer RJ, Codd MB, Ballard DJ, Fuster V, Gersh BJ. The clinical course of idiopathic dilated cardiomyopathy. A population-based study. Ann Intern Med 1992;117:117-23.

5 Cohn JN, Johnson G, Ziesche S, Cobb F, Francis G, Tristani F, et al. A comparison of enalapril with hydralazine-isosorbide dinitrate in the treatment of
chronic congestive heart failure. N Engl $\mathcal{G}$ Med 1991;325: 303-10.

6 CONSENSUS trial study group. Effect of enalapril on mortality in severe congestive heart failure: results of the Cooperative North Scandinavian Enalapril Survival Study (CONSENSUS). $N$ Engl $f$ Med 1987;316: 1429-35.

7 The SOLVD Investigators. Effect of enalapril on mortality and the development of heart failure in asymptomatic and the development of heart failure in asymptomatic patients with reduced left ventricul

8 The SOLVD Investigators. Effect of enalapril on survival in patients with reduced left ventricular ejection fraction and congestive heart failure. $N \mathrm{Engl} f \mathrm{Med} 1991 ; 325$ : 293-302

9 Swedberg K, Waagstein F, Hjalmarson S, Wallentin I. Prolongation of survival in congestive cardiomyopathy by beta receptor blockade. Lancet 1979;1:1374-6.

10 Anderson JL, Lutz JR, Gilbert EM, Sorenson SG Yanowitz FG, Menlove RL, et al. A randomized trial of low dose beta-blockade therapy for idiopathic dilated cardiomyopathy. Am $\mathcal{\text { C Cardiol } 1 9 8 5 ; 5 5 : 4 7 1 - 5 \text { . }}$.

11 Report of the WHO/ISFC task force on the definition and classification of cardiomyopathies. Br Heart $\mathcal{f} 1980 ; 44$ : 672-3.

12 Aretz HT, Billingham ME, Edwards WD, Factor SM, Fallon JT, Fenoglio J Jr, et al. Myocarditis: A histopathologic definition and classification. Am $\mathcal{f}$ Cardiovas Pathol 1987;1:3-14.

13 Criteria Committee of the New York Heart Association. Nomenclature and criteria for diagnosis of the heart and great vessels. 6th ed. Boston: Little, Brown; 1964;1-23.

14 Lee DCS, Johnson RA, Bingham JB, Leahy M, Dinsmore $\mathrm{RE}$, Goroll AH, et al. Heart failure in outpatients. A randomized trial of digoxin versus placebo. $N \mathrm{Engl} f \mathrm{Med}$ 1982;306:699-705.

15 Kaplan EL, Meier P. Non parametric estimation from incomplete observation. f Am Statist Ass 1958;53: 457-81.

16 Tarone ER. Tests for trend in life table analysis. Biometrika 1975;62:679-82.

17 Tarone ER, Ware J. On distribution-free test for equality of survival distributions. Biometrika 1977;64:156-60.

18 Lee ET, Desu MM, Gehan EA. A Monte Carlo study of the power of some two-sample tests. Biometrika 1975; 62:425-32.

19 Cox DR. Regression models and life-tables. $\mathcal{F}$ Roy Statist Soc 1972;34, Series B:187-220.

20 Gavazzi A, Lanzarani L, Cornalba C, Desperati M Raisaro D, Angoli L, et al. Dilated (congestive) cardiomyopathy. G Ital Cardiol 1984;14:492-8.

21 Ikram H, Williamson HG, Won Michael, Crozier I, Wells EJ. The course of idiopathic dilated cardiomyopathy in New Zealand. Br Heart $\mathcal{f}$ 1987;57:521-7.

22 Komajda M, Iais JP, Reeves F, Goldfarb B, Bouhour JB, Juilliere $\mathrm{Y}$, et al. Factors predicting mortality in idiopathic dilated cardiomyopathy. Eur Heart $\mathcal{f} 1990 ; 11$ : 824-31.

23 Diaz RA, Obasohan A, Oakley CM. Prediction of outcome in dilated cardiomyopathy. Br Heart $\mathcal{F}$ 1987;58:393-9.

24 Razzolini R, Boffa GM, Stritoni P, Bufano S, Ramondo A Rampazzo C, et al. Storia naturale delle miocardiopatie dilatative. G Ital Cardiol 1989;19:114-20.

25 Unverferth DV, Magorien RD, Moeschberger MV, Baker PB, Fetters JK, Leier CV. Factors influencing the oneyear mortality of dilated cardiomyopathy. Am $\mathcal{f}$ Cardio 1984;54:147-52.

26 Hofmann T, Meinertz T, Kasper W, Geibel A, Zehender M, Hohnloser S, et al. Mode of death in idiopathic dilated cardiomyopathy: multivariate analysis of prognostic determinants. Am Heart $\mathcal{F} 1988 ; 116: 1455-63$.

27 Keogh AM, Freund J, Baron DW, Hickie JB. Timing of cardiac transplantation in idiopatic dilated cardiomyopathy. Am ₹ Cardiol 1988;61:418-22.

28 Likoff MJ, Chandler SL, Kay HR. Clinical determinants of mortality in chronic congestive heart failure secondary to idiopathic dilated or to ischemic cardiomyopathy. $\mathrm{Am}$ 7 Cardiol 1987;59:634-38.

29 Packer M, Lee WH, Kessler PD, Gottlieb SS, Bernstein JL, Kukin ML. Role of neurohormonal mechanisms in determining survival in patients with severe chronic heart failure. Circulation 1987;75(suppl IV):80-92.

30 Packer $M$. The neurohormonal hypothesis: a theory to explain the mechanism of disease progression in hear failure. F Am Coll Cardiol 1992;20:248-54.

31 Cohn JN, Levine TB, Olivari MT, Garberd V, Lura D, Francis GS, et al. Plasma norepinephrine as guide to prognosis in patients with chronic congestive heart failure. $N$ Engl $\mathcal{F}$ Med 1984;311:819-23.

32 Swedberg K, Eneroth P, Kjekshus J, Wilhelmsen L for the CONSENSUS study group. Hormones regulating cardiovascular function in patients with severe congestive diovascular function in patients with severe congestive 1990;82:1730-6.

33 Engelmeier RS, O'Connell JB, Walsh R, Rad N, Scanlon PJ, Gunnar RM. Improvement in symptoms and exercise tolerance by metoprolol in patients with dilated cardiomyopathy: a double blind, randomized, placebo controlled trial. Circulation 1985;72:526-46.

34 Gilbert EM, Anderson JL, Deitchman D, Yanowitz FG, O'Connell JB, Renlund DG, et al. Long-term $\beta$-blocker vasodilator therapy improves cardiac function in idiopathic dilated cardiomyopathy: a double-blind, randomized study of bucindolol versus placebo. $\mathrm{Am} 7 \mathrm{Med}$ 1990;88:223-9.

35 Waagstein F, Caidahl $\mathrm{K}$, Wallentin I, Bergh $\mathrm{CH}$, Hjalmarson A. Long term beta blockade in dilated cardiomyopathy. Circulation 1989;80:551-63.

36 Sinagra G, Perkan A, Di Lenarda A, Lardieri G, Pinamonti B, Mestroni L, et al. I betabloccanti nella terapia della cardiomiopatia dilatativa: revisione della letteratura ed esperienza clinica su 67 pazienti. G Ital Cardiol 1992;22:969-89.

37 Urbach $P$. The value of randomization and control in clinical trials. Statistics in Medicine 1993;12:1421-31. 